P1-108 IMPACT OF THE SMOKEFREE LEGISLATION ON SMOKING BEHAVIOUR AND ATTITUDES OF OUITTING AMONG FATHERS WITH INFANTS UNDER 18 MONTHS IN HONG KONG: A CROSS-SECTIONAL STUDY

doi:10.1136/jech.2011.142976d.1

${ }^{1} \mathrm{~S} S \mathrm{C}$ Chan, ${ }^{*}{ }^{1} \mathrm{D}$ Y P Leung, ${ }^{1} \mathrm{~J} \mathrm{PL}$ Yau, ${ }^{1} \mathrm{~A}$ Y M Leung, ${ }^{1} \mathrm{G} \mathrm{M}$ Leung, ${ }^{2} \mathrm{~K}$ Emmons, ${ }^{1} \mathrm{~T} \mathrm{H}$ Lam. ${ }^{1}$ The University of Hong Kong, Hong Kong, Hong Kong; ${ }^{2}$ Harvard University, Boston, USA

Introduction Hong Kong has implemented the Smokefree legislation since January 2007 and smoking is prohibited in vast public and covered areas thereafter. The Smoke free legislation aims to protect people from exposing to SHS and motivating smokers to quit. This study explored the effect of the legislation on the smoking behaviour and their attitudes of quitting among fathers of newborn babies.

Methods This is a cross-sectional survey on families with a smoking father, a non-smoking mother and an infant under 18 months recruited at the Maternal and Child Health Centres from June 2008 to October 2009. Frequencies showed the changes in fathers' household smoking behaviour and their attitudes of quitting after the legislation. Results 1112 fathers completed the baseline questionnaire and their mean age was $35.5( \pm 7.0)$ years and had been smoking for 17.9 $( \pm 7.2)$ years. $96 \%(1054 / 1097)$ were aware of the legislation, $27.3 \%$ (299/1097) reported they had less SHS exposure and 27\% (296/1097) had smoked less at home after the enactment of the legislation. However, the majority of them had no changes in their desire to quit $(63.7 \%, 699 / 1097)$, perceived importance of quitting $(70.3 \%, 771 /$ 1097), perceived confidence of quitting (73\%, 801/1097) and perceived difficulty of quitting $(75.6 \%, 829 / 1097)$ compared before the legislation.

Conclusion This study showed that some fathers improved their smoking behaviours after the Smokefree legislation but a majority had no change in attitudes towards quitting. The HK government should therefore promote the importance of quitting to the public and allocate more resources to the smoking cessation services.

\section{P1-109 THE WCRF/AICR CONTINUOUS UPDATE PROJECT: DIETARY FIBRE INTAKE AND COLORECTAL CANCER INCIDENCE}

doi:10.1136/jech.2011.142976d.2

${ }^{1} \mathrm{D}$ Chan, ${ }^{*}{ }^{1} \mathrm{R}$ Lau, ${ }^{1} \mathrm{D}$ Aune, ${ }^{1} \mathrm{R}$ Vieira, ${ }^{2} \mathrm{D}$ Greenwood, ${ }^{3} \mathrm{E}$ Kampman, ${ }^{1} \mathrm{~T}$ Norat. ${ }^{1}$ Imperial College London, London, UK; ${ }^{2}$ University of Leeds, Leeds, UK; ${ }^{3}$ Wageningen University and Research Centre, Wageningen, The Netherlands

Introduction In the WCRF/AICR $2^{\text {nd }}$ expert report, it was concluded that foods containing dietary fibre probably decreases colorectal cancer risk. As part of the WCRF Continuous Update Project, we updated the associations between dietary intake of total fibre and by dietary sources, and colorectal cancer incidence.

Methods Relevant prospective studies were identified in PubMed until May 2010. Random effect dose-response meta-analyses were performed on total dietary fibre, and specifically fruit, vegetable, legume, and cereal fibres and colorectal cancer risk. Heterogeneity between studies was assessed by $I^{2}$ statistic.

Results Total dietary fibre intake was inversely and statistically significantly associated with colorectal cancer. The summary RR for $10 \mathrm{~g} /$ day increase was 0.90 (95\% CI 0.86 to $0.94,15$ studies). Similar association was observed in cereal fibre $\left(R_{10 g}\right.$ day $=0.90,95 \% \mathrm{CI}$ 0.83 to $0.97,8$ studies $)$ but not in fruit fibre $\left(R_{10}\right.$ g/day $=0.93,95 \% \mathrm{CI}$ 0.82 to $1.05,9$ studies $)$, vegetable fibre $\left(R_{10 \mathrm{~g} / \text { day }}=0.98,95 \% \mathrm{CI} 0.91\right.$ to $1.06,9$ studies $)$, and legume fibre $\left(R_{10 \mathrm{~g} / \text { day }}=0.62,95 \% \mathrm{CI} 0.27\right.$ to $1.42,4$ studies). There was no evidence of heterogeneity between studies.

Conclusion The overall results of cohort studies indicate that high intake of dietary fibre is inversely associated with decreased color- ectal cancer risk. The protective effect is more evident for fibre from cereal sources. More studies in different populations are needed to confirm this observation.

\section{P1-110 PREVALENCE OF OVERWEIGHT AND OBESITY AMONG THE MIDDLE AND OLD-AGED IN EASTERN CHINA, 2010}

doi:10.1136/jech.2011.142976d.3

${ }^{1} \mathrm{M}$ Jin, ${ }^{1} \mathrm{M}$ Zhang, ${ }^{1} Y \mathrm{Wu},{ }^{1} \mathrm{Y} Y \mathrm{Y}^{2}{ }^{2} \mathrm{~J} \mathrm{Gu},{ }^{3} Y \mathrm{Ji},{ }^{1} \mathrm{Z}$ Huang, ${ }^{1} Y$ Pan, ${ }^{1} \mathrm{X}$ Jiang, ${ }^{1} Y$ Mao, ${ }^{1} \mathrm{~K}$ Chen. ${ }^{*}{ }^{1}$ Zhejiang University School of Public Health, Hangzhou, Zhejiang Province, China; ${ }^{2}$ Township Health Centers of Yaozhuang, Jiashan, Zhejiang Province, China; ${ }^{3}$ Township Health Centers of Dingzha, Jiashan, Zhejiang Province, China

In the past decade, the prevalence of overweight and obesity in Chinese has increased markedly, especially in regions economy developing quickly. And the ageing also has been an increasing social problem. To obtain current estimates of overweight and obesity among the middle and old-aged ( 45 years or older) in economy developed region, a census study was carried out. Overweight and obesity was defined as a BMI of 24 or higher and 28 or higher, respectively. A regional representative sample (3740 males, 5174 females) was included in by a multi-stage cluster sampling method from Zhejiang Province. The prevalence of overweight and obesity were $33.4 \%$ and $8.1 \%$ among 45 - through 59 -years-old, and $33.7 \%$ and $8.2 \%$ among 60 years or older for males, and $38.3 \%$ and $11.2 \%$, $37.8 \%$ and $11.8 \%$ for females, respectively. Females had a much higher prevalence of overweight or obesity than males $(p<0.000)$. However, no significant difference existed by age. Compared with a national sampling survey in 2002, those were $26.3 \%$ and $7.2 \%$, and $23.5 \%$ and $6.6 \%$ for males, and $31.4 \%$ and $12.9 \%$, and $25.2 \%$ and $11.9 \%$ for females, respectively. Not only the prevalence of obesity in females maintained in a comparative high level, the prevalence of overweight and obesity in males and overweight in females also increased evidently. These results suggest that the prevalence of overweight and obesity among the middle and old-aged is a serious social problem. We should pay enough attention to the body weight control issue among them with the arrival of the ageing society.

\section{P1-111 PREVALENCE AND PSYCHOSOCIAL DETERMINANTS OF SMOKING AND PASSIVE SMOKING IN OLDER PEOPLE IN RURAL AND URBAN CHINA: A MULTICENTER COMMUNITY-BASED STUDY}

doi:10.1136/jech.2011.142976d.4

${ }^{1} \mathrm{R}$ Chen, ${ }^{*} \mathrm{D}$ Zhang. ${ }^{1}$ University of Wolverhampton, Wolverhampton, UK; ${ }^{2}$ Anhui Medical University, Hefei, China

Background The prevalence and psychosocial determinants of smoking and passive smoking in older people in China are not well documented.

Methods Using a standard interview method, we examined random samples of 6071 participants aged $\geq 60$ years in Anhui, Guangdong, Heilongjiang, Shanghai and Shanxi provinces, China during 2007-2009. The smoking and passive smoking questionnaire was derived partly from the Scottish MONICA survey.

Results World age-standardised prevalence for current and former smoking in men was $45.6 \%$ (95\% CI $42.6 \%$ to $48.6 \%$ ) and $20.5 \%$ ( $18.6 \%$ to $22.4 \%$ ), and in women $11.1 \%$ (9.87\% to $12.3 \%$ ) and $4.49 \%$ (3.73\% to $5.26 \%$ ). Age-gender adjusted OR for current and former smoking was significantly with younger age (for current-smoking), male gender, low levels of education, occupational class and annual income, living in rural area, less satisfaction for life, alcohol drinking, widow status, having no religion, pessimism (for current-smoking), worrying and depressive syndrome. Among 3774 never-smokers, 
1160 had passive smoking (prevalence of $31.5 \%, 29.5 \%$ to $33.5 \%$ ), $53 \%$ of which was from exposure at home only. Its risk was significantly related to female gender, low levels of education, occupational class and annual income, living in rural area, less satisfaction for life, being married, alcohol drinking, and having a religion.

Conclusions There is a high level of smoking in Chinese older men and of passive smoking in women. Differences between active and passive smoking in association with marital status and having a religion may reflect less success in controlling smoking and passive smoking in China. The associations of smoking and passive smoking with psychosocial factors suggest priority preventive strategies.

\section{P1-112 ANTENATAL PREDICTION OF POOR MATERNAL AND CHILD OUTCOMES: IMPLICATIONS FOR SELECTION INTO INTENSIVE PARENTING SUPPORT PROGRAMS}

doi:10.1136/jech.2011.142976d.5

\begin{abstract}
${ }^{1,2} \mathrm{C}$ Chittleborough, ${ }^{* 1,3} \mathrm{D}$ Lawlor, ${ }^{1,2} \mathrm{~J}$ Lynch. ${ }^{1}$ School of Social and Community Medicine, University of Bristol, Bristol, UK; ${ }^{2}$ Sansom Institute for Health Research, Division of Health Sciences, University of South Australia, Adelaide, Australia; ${ }^{3}$ MRC Centre for Causal Analysis in Translational Epidemiology, University of Bristol, Bristol, UK
\end{abstract}

Objective To determine which factors are the best predictors of poor maternal and child outcomes up to age 5, so that parent support program can better target interventions to those who will benefit most.

Methods The Avon Longitudinal Study of Parents and Children is a prospective birth cohort of 14541 pregnant women. Childhood development was assessed with a parent-reported developmental scale at 18 months $(n=7969)$, the Strengths and Difficulties Questionnaire at 47 months $(n=8328)$ and teacher-reported School Entry Assessment scores at $4-5$ years $(n=7345)$. Maternal outcomes were depression at 8 weeks $(n=10070)$, never breastfeeding up to 6 months $(n=7976)$, feelings of unattachment $(n=8253)$ and hostility $(n=8159)$ at 47 months, and not in employment, education or training $(n=8265)$ at 61 months.

Results Few families with each poor outcome (3\% to 9\%) had mothers aged $<20$ years when they were pregnant. Half to threequarters of families with poor outcomes could be identified if information on all six predictors was used and a woman had at least one of these. Model discrimination (area under the receiver operator characteristic curve) improved from approximately 0.50 for all outcomes using maternal age only, up to 0.80 for postnatal depression when all six predictors were included in the model. Calibration also improved with the model including all six characteristics.

Discussion Factors other than young maternal age, including education, smoking and depression during pregnancy should be considered in identifying those eligible for programs aimed at improving child and maternal outcomes through intensive parent support.

\section{P1-113 PATIENT SATISFACTION WITH URBAN AND RURAL INSURANCE AND FAMILY PHYSICIAN PROGRAM IN MARKAZI PROVINCE}

doi:10.1136/jech.2011.142976d.6

M Taheri, ${ }^{*}$ A Amani, R Zahiri, M Mohammadi. Arak University of Medical Sciences, Arak- markazi, Iran

Introduction Family physician plan is one of the basic programs of the Fourth Plan on Economic, Social and Cultural Development in the health sector. This program more than 5 years old is going, is currently deployed in all villages and urban areas with populations $<20000$ people in Iran. This study was conducted with the aim of measuring User's Satisfaction from Urban to Rural Insurance and Family Practice Program in Markazi Province in the fall of 2009.

Materials and Methods This study is a descriptive-analytic and cross sectional, is done at 40 medical centers with family doctor services in the province. Demographic characteristics of individuals, personnel behaviour, spending time, guidance and training, service costs, adequacy of services, ability and skills of personnel, access to medical facilities, adequacy of facilities and equipment based on a questionnaire and interview patients or their relatives were registered. Results 391 people were interviewed during the 3 months. The average age of $38.24 \pm 17.02$ years, $66.5 \%$ of them women and $81.3 \%$ of them, were married. $34.52 \%$ of patients in high or very high were satisfied with the whole performance of health centers. This High or very high level of satisfaction was about the performance of family physicians, midwives, laboratory and pharmacy, respectively 33.1, 37.1, 36.8 and 38.3.

Conclusion In total, the program has been successful in the province. Policymakers can to achieve a higher level of satisfaction in the long term based on comments and service recipients and promoting program with some program processes.

\section{P1-113A EPIDEMIOLOGICAL PATTERN OF INJURY BY DISTRICT IN TEHRAN}

doi:10.1136/jech.2011.142976d.7

${ }^{1} \mathrm{~S} J$ Shamsnia, ${ }^{* 1,2} \mathrm{~A}$ Farshad, ${ }^{1,2} \mathrm{~A}$ Moghisi. ${ }^{1}$ Islamic Azad University, Firouzabad, Iran; ${ }^{2}$ Tehran Municipality, Tehran, Iran

Introduction Tehran is the capital city of IR Iran with about 12000000 inhabitants. Consisting of 22 districts. Injuries happen with different rate and type in different zones.

Methods $10 \%$ of population of Tehran considered for the households survey based on Urban HEART (urban Health Equity Assessment and Response Tool) interviewer were trained uniformly. The result will be used as a baseline for the future assessment.

Results Females are mostly involved in fall, burn and poisoning while men are mostly involved in traffic accidents, interpersonal violence and electric shocks. Most accidents were among families with 3-5 members. Aged 15-40 years old from the low income groups were affected more. In traffic accident the young males are the most affected victims more are living in districts 14 , 15, 18, 9, 19 \& 4 respectively. In district 11,12, 14 most of the victims were motorcyclists. In districts 2,3 \& 5 victims were pedestrians predominantly. Children and old ages are the victims of Fall, there is no gender differences in most of the districts area except in district 19 where males are falling twice than females and in districts 1, 2, 3 $\& 12$ this ratio is vice versa $(p \leq 0.05)$. Burns were more recorded in districts $13,16,17,12$ respectively and the least from districts 3,2 , \& 5. At the level of $\mathrm{p} \leq 0.05$ with $95 \%$ CI differences between districts were significant.

Conclusion Tehran is mega city. By knowing the districts characteristics and sex and age differences, the urban managements will be improved through better policy making.

\section{P1-114 WEIGHT CHANGE SINCE AGE 20 AND CARDIOVASCULAR DISEASE (CVD) MORTALITY: THE OHSAKI STUDY}

doi:10.1136/jech.2011.142976d.8

W T Chou, ${ }^{*}$ M Kakizaki, Y Tomata, M Nagai, S Kuriyama, I Tsuji. Division of Epidemiology, Department of Public Health and Forensic Medicine, Tohoku University Graduate School of Medicine, Sendai, Japan

Introduction Long-term weight change since young-adulthood is a better indicator of distribution of body fat mass. We investigated 